Article

\title{
Microwave Irradiation-Assisted Synthesis of a Novel Crown Ether Crosslinked Chitosan as a Chelating Agent for Heavy Metal Ions $\left(\mathbf{M}^{+\mathbf{n}}\right)$
}

\author{
Awwad A. Radwan ${ }^{1,2}$, Fars K. Alanazi ${ }^{1,3}$ and Ibrahim A. Alsarra ${ }^{3,4, *}$
}

1 College of Pharmacy, King Saud University, P.O. Box 2457, Riyadh 11451, Saudi Arabia

2 Department of Pharmaceutical Organic Chemistry, Faculty of Pharmacy, Assiut University, Assiut-71527, Egypt

3 Department of Pharmaceutics, College of Pharmacy, King Saud University, P.O. Box 2457, Riyadh 11451, Saudi Arabia

4 Center of Excellence for Research in Engineering Materials, CEREM, Room 2A-138, College of Engineering, King Saud University, P. O. Box 800, Riyadh 11421, Saudi Arabia

* Author to whom correspondence should be addressed; E-Mail: ialsarra@ksu.edu.sa;

Tel.: +966-1-4677504; Fax: +966-1-4676363.

Received: 23 June 2010; in revised form: 18 August 2010 / Accepted: 2 September 2010 /

Published: 6 September 2010

\begin{abstract}
Microwave irradiation was used to obtain a di-Schiff base type crosslinked chitosan dibenzocrown ether $(\mathrm{CCdBE})$ via the reaction between the $-\mathrm{NH}_{2}$ and $-\mathrm{CHO}$ groups in chitosan and 4,4'-diformyldibenzo-18-c-6, respectively. The structure of the synthesized compound was characterized by elemental analysis, solid state ${ }^{13} \mathrm{C}-\mathrm{NMR}$ and FT-IR spectra analysis. The results showed that the mass fraction of nitrogen in the CCdBE derivative was much lower than those of chitosan. The FT-IR spectra of CCdBE revealed the expected chitosan-crown ether structure, as evidenced by the presence of the characteristic $\mathrm{C}=\mathrm{N}$ and Ar peaks. The adsorption properties of $\mathrm{CCdBE}$ for $\mathrm{Pd}^{2+}$ and $\mathrm{Hg}^{2+}$ were investigated and the results demonstrated that the adsorbent has both desirable adsorption properties with a high particular adsorption selectivity for $\mathrm{Hg}^{2+}$ when in the presence of $\mathrm{Pb}^{2+}$ as well as selectivity coefficients for metal ions of $K_{\mathrm{Hg}}{ }^{2+} / \mathrm{Pb}{ }^{2+}=8.00$ and $K_{\mathrm{Hg}}{ }^{2+} / \mathrm{Pb}{ }^{2+}=10.62$ at $\mathrm{pH}$ values of 4 and 6 , respectively. The reusability tests for CCdBE for $\mathrm{Pb}^{2+}$ adsorption showed that complete recovery of the ion was possible with $\mathrm{CCdBE}$ after 10-multiple reuses while CTS had no reusability at acidic solution because of its higher dissolution. The studied features of CCdBE suggested that the material could be
\end{abstract}


considered as a new adsorbent. It is envisaged that the crosslinking of CTS into CCdBE would enhance practicality and effectiveness of adsorption in ion separation and removal procedures.

Keywords: chitosan; crown ether; adsorption

\section{Introduction}

Heavy metals are highly toxic at low concentrations and can accumulate in living organisms, causing several disorders and diseases [1,2]. As a result of industrialization and urbanization, the presence of heavy metal ions in water streams has increased greatly in the last fifty years. Removal of heavy metal ions from wastewater is essential because of their extreme environmental, public health and economic impacts [3].

The main techniques that have been used for metal content reduction from industrial waste are chemical precipitation, ion exchange, membrane filtration, electrolytic methods, reverse osmosis, solvent extraction, and adsorption [4-6]. However, these methods are limited by high operational costs and/or may also be inefficient in the removal of some toxic metal ions, particularly at trace level concentrations $[7,8]$.

The use of chelation ion exchange for wastewater remediation has gained considerable attention in recent years. Chelation ion exchange, in contrast to simple ion exchange, has the advantage of only removing toxic metal ions while the harmless ions move on into the environment [9]. Some of the best chelation ion-exchange materials consist of different biopolymers and their derivatives because of the variety of functional groups, like $-\mathrm{OH}$ and $-\mathrm{NH}_{2}$, with which other chemical moieties, e.g., metal ions, can easily react and bond. These biopolymers, including cellulosics, alginates, proteins, chitin and chitin derivatives have remarkable capabilities of lowering metal ion concentrations to parts per billion levels $[9,10]$. For example, chitosan (CTS) is a deacetylated derivative of chitin that can adsorb metals due to its amino and hydroxyl groups. However, CTS can be dissolved in acidic media which limits its recycling in adsorption processes. Crosslinked chitosan synthesized by the reaction of CTS with hydrophobic crosslinking agents can overcome the disadvantages of CTS and still maintain good adsorption properties for many metal ions. Also, modifications to increase the number of binding sites and/or binding surfaces of chitosan have been made both by substitution on the amino group at C-2 or by crosslinking the polyglycans with small chemicals. Crosslinking CTS with biomass/biopolymers (e.g., alginate) [1,2], chelators such as ethylenediamine tetraacetic acid (EDTA) [11], fixatives such as glutaraldehyde (GA) [12] or polymers like polyvinyl alcohol (PVA) [13] creates a three-dimensional network within the biopolymer and increases the internal surface area for metal adsorption. Increase in structural and chemical stability of these crosslinked derivatives contributes to the resistance and endurance of acid [2] from surface and subsurface groundwater [14-16], thereby improving water/sewage purification treatments.

Because crown ethers have particular molecular structures, they have good and different complex selectivity for many metal ions. However, they are not recycled easily after use, so their applications are limited. If crown ethers were crosslinked to chitosan chains to give crown ether-crosslinked 
chitosan containing double structures and displaying the properties of chitosan and crown ethers, these novel chitosan derivatives would have stronger complex formation with better selectivity for metal ions than the corresponding crown ethers and chitosan separately [17].

Scheme 1. Reaction scheme for the synthesis of CcdBE.<smiles>O=Cc1ccc(O)c(O)c1</smiles>

(1)<smiles>O=Cc1ccc(OCCOCCOc2ccc(C=O)cc2O)c(O)c1</smiles>

(2)

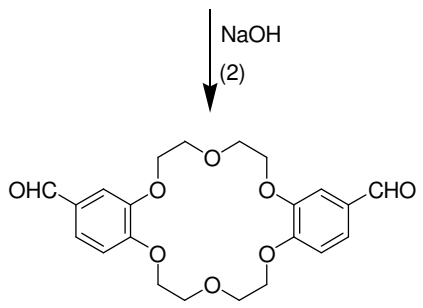

(3)

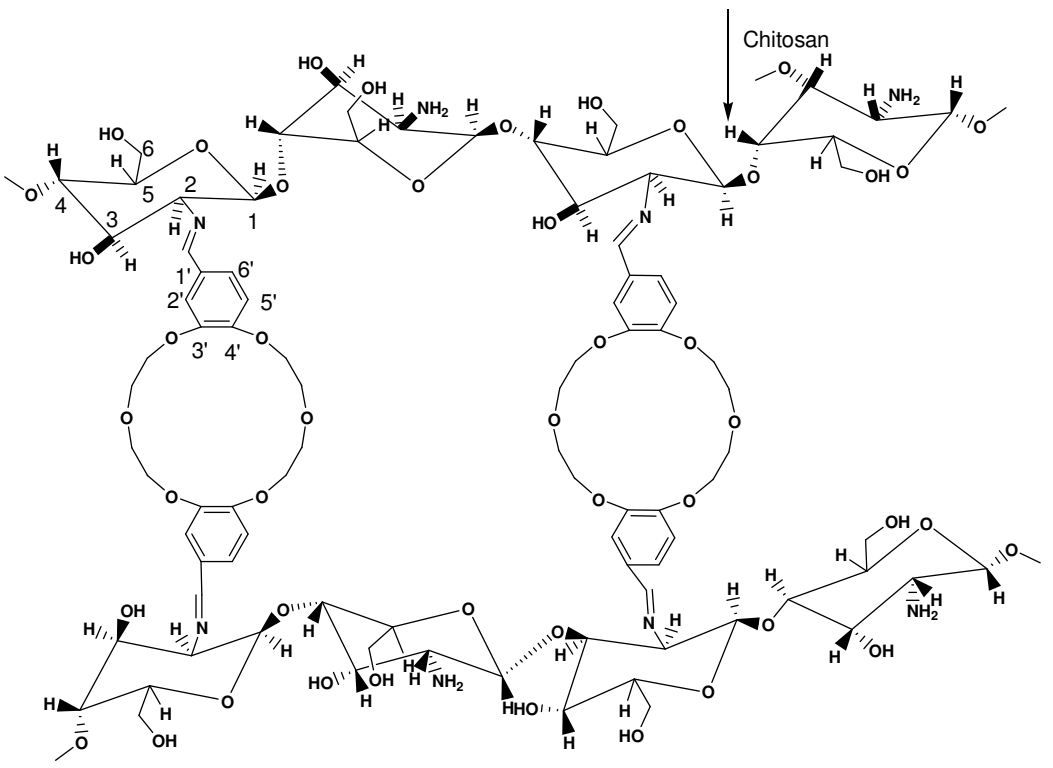

(4)

Recently, microwave-assisted reactions have received much attention due to the higher conversions and shorter reaction times possible under microwave irradiation compared to those of conventional heating [18]. As a result, microwave irradiation as a chemical reaction means has been widely applied in various synthetic fields of chemistry such as organic and polymer synthesis [19]. In this work, we applied microwave technology to prepare a crosslinked chitosan dibenzocrown ether (CCdBE). This work thus serves as not only an expansion of the applications of microwave irradiation in reactions, but also as an expansion of the use of chitosan as an adsorbent for heavy metal removal. The chitosan derivative (CCdBE) was synthesized by the reaction of 4,4'-diformyldibenzo-18-crown- 6 crown ether with CTS under microwave irradiation to give a $\mathrm{N}$-Schiff base type crosslinked chitosan dibenzo-18crown-6 (CCdBE) [20]. 4,4'-Diformyldibenzo-18-crown-6 was chosen because it was expected that the introduction of 4,4'-diformyldibenzocrown ether residues into chitosan could significantly enhance 
the adsorption ability compared with the parent CTS, making it possible for this CTS derivative to show promising applications in water treatment.

The structure of the synthesized compound was confirmed by FT-IR spectra analysis, solid state ${ }^{13} \mathrm{C}-\mathrm{NMR}$, elemental analysis and X-ray powder diffraction analysis. The adsorption of lead and mercury ions by CCdBE was studied and it showed that the cross linking of CTS into CCdBE could enhance the practicality and effectiveness of adsorption in ion separation and removal procedures.

\section{Results and Discussion}

\subsection{Synthesis and Structural Characterization of Chitosan-Crown Ether}

Chitosan crosslinked with dibenzo-18-crown-6 ether (CCdBE) was synthesized as shown in Scheme 1. The three-dimensional structure of the minimized conformation (Figure 1) of CCdBE showed that the crown ether rings were perpendicular to the crosslinked chitosan chains, which represent a series of parallel circular cavities passing over a cylindrical groove between the two crosslinked chitosan chains.

Structure elucidation of crown ether crosslinked-chitosan (CCdBE) was accomplished by elemental analysis, FT-IR spectral analysis, X-ray diffraction analysis and solid state ${ }^{13} \mathrm{C}-\mathrm{NMR}$ analysis. The CCdBE derivative did not dissolve in organic solvents such as dimethylsulfoxide (DMSO), chloroform, formamide, dimethylformamide (DMF) and trifluoroacetic acid.

Figure 1. Three-dimensional (3D) view of CcdBE.

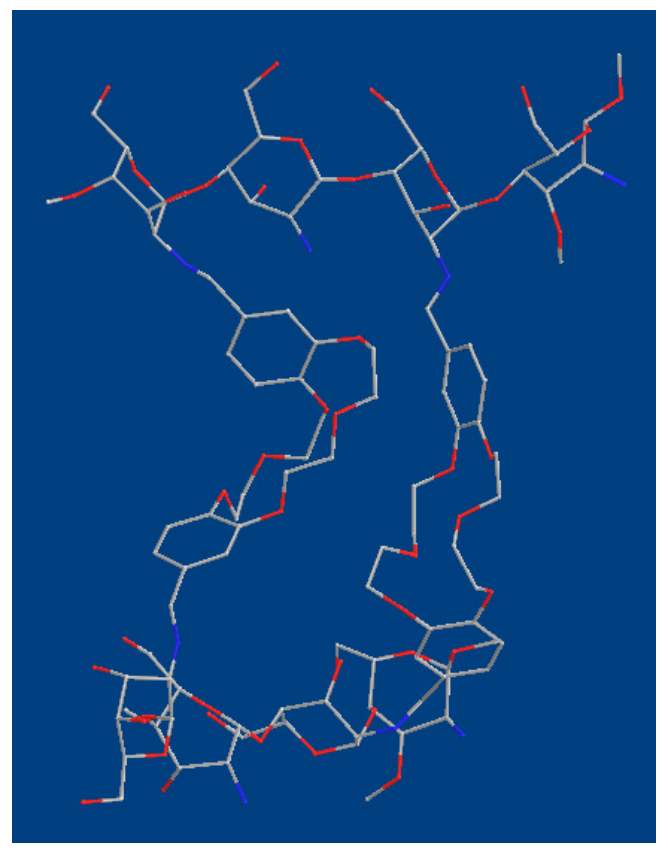

\subsubsection{Elemental Analysis}

The elemental analysis results and degree of substitution (DS) of CTS and CCdBE are presented in Table 1. The nitrogen content of CCdBE was much lower than that of CTS. It was thought that the difference was attributable to the fact that the cross linker molecule (4',4"-formyldibenzo-18-crown-6) 
does not have nitrogen atoms in its structure and although it had been grafted to chitosan by -CHO and $-\mathrm{NH}_{2}$ reaction, it only added carbon, oxygen and hydrogen atoms to $\mathrm{CCdBE}$, decreasing the relative content of nitrogen in this molecule. Hydrogen content also decreased due to water elimination during the graft reaction and carbon content increased due to the high carbon content on cross linker molecule.

Table 1. Elemental analysis of chitosan (CTS) and crosslinked chitosan (CCdBE).

\begin{tabular}{lllll}
\hline Compound & N\% & C\% & H\% & DS\% \\
\hline CTS & 6.20 & 38.30 & 6.70 & - \\
CCdBE & 3.60 & 46.55 & 6.25 & 42 \\
\hline
\end{tabular}

\subsubsection{Infrared Analysis}

The IR spectra of chitosan and the derivative are shown in Figure 2. Although marked differences were not observed in the IR spectra, a characteristic $\mathrm{C}=\mathrm{N}$ stretch vibration peak appeared at $1635 \mathrm{~cm}^{-1}$ due to the presence of the Schiff base groups produced in the course of the reaction (from chitosan to chitosan-crown ether).

Figure 2. FTIR spectra of the chitosan (upper) and crosslinked chitosan (lower).
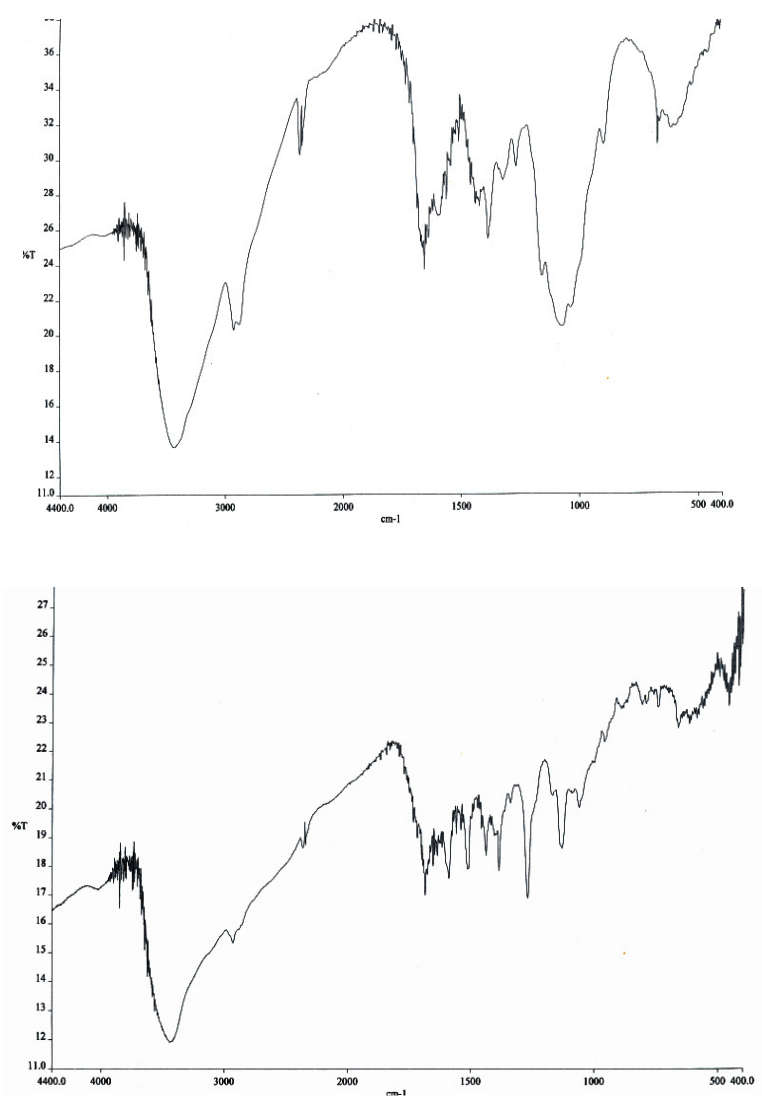

\subsubsection{X-ray Diffraction Analysis}

The X-ray diffraction patterns of chitosan (CTS) and crosslinked chitosan (CCdBE) are shown in Figure 3. It shows the characteristic peaks of chitosan (CTS) at $2 \theta=10^{\circ}$ and $20^{\circ}$, which indicate a high 
degree of crystallinity for this substance [21,22]. The results revealed that the peak at $2 \theta=10^{\circ}$ disappeared and the peak at $2 \theta=20^{\circ}$ decreased in crosslinked chitosan (CCdBE). It appeared that CCdBE didn't exhibit any crystallinity peak. It was thought that the decrease in crystallinity of CCdBE could be attributed to deformation of the strong hydrogen bond in the chitosan backbone chain because the amino groups were substituted by 4',4"-diformyldibenzo-18-crown-6. The obtained results were in reasonable agreement with the published data of Xin-Hu et al. [23] who suggested that the crystallinity of chitosan was decreased when it is converted into a $N$-Schiff base-type benzo-21-crown-7 chitosan [23].

Figure 3. X-ray diffraction patterns of chitosan (in red) and crosslinked chitosan (blue).

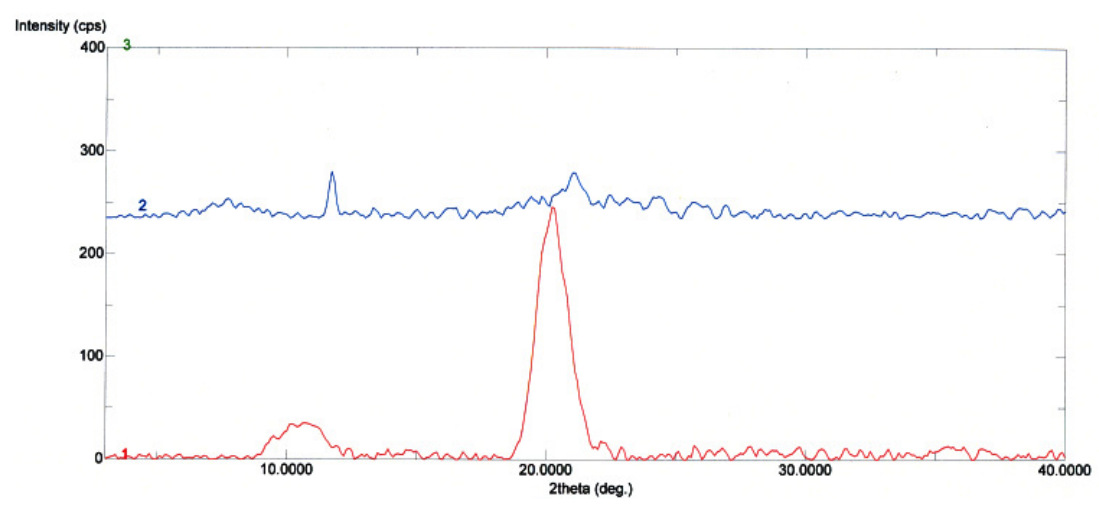

\subsubsection{Solid-State ${ }^{13} \mathrm{C}-\mathrm{NMR}$ Analysis}

The Solid-State ${ }^{13} \mathrm{C}-\mathrm{NMR}$ spectrum for crosslinked chitosan are shown in Figure 4. Characteristic aromatic carbon peak appeared at 127 ppm while the characteristic peak of carbon in $\mathrm{C}=\mathrm{N}$ groups occurred at $148 \mathrm{ppm}$.

Figure 4. Solid-state ${ }^{13} \mathrm{C}$ NMR spectrum of crosslinked chitosan (CCdBE).

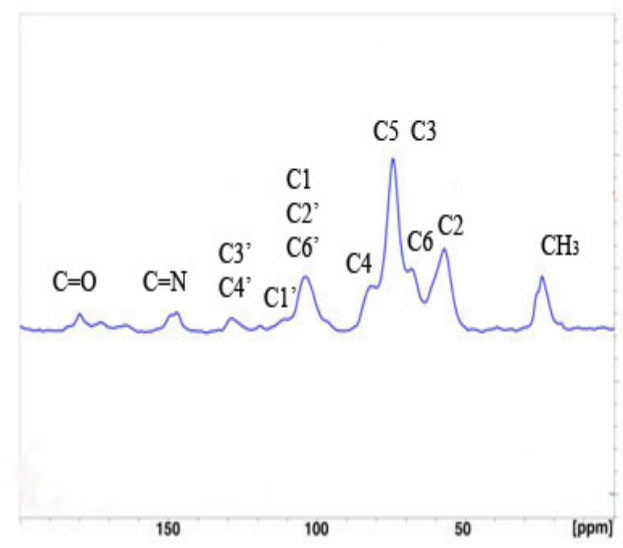

\subsubsection{Scanning Electron Microscopy (SEM) Studies}

Scanning electron microscope images of the surface of chitosan (CTS) and the crosslinked chitosan (CCdBE) are shown in Figures 5a,b. The surface morphology of chitosan (Figure 5a) was smooth, whereas the crosslinked chitosan (CCdBE, Figure $5 b$ ) exhibited a bean-like shaped granulated surface 
with high cavity-shaped porosities. The porous structure of $(\mathrm{CCdBE})$ may be formed due to the bridging connection of diformyldibenzo-18-crown-6 molecules, hydrophobic in nature, between the different amine groups in CTS, hydrophilic surface, through the intra-molecular and/or inter-molecular crosslinking interactions that leads to deformation of the strong hydrogen bond in the chitosan backbone chain and resulted in an amorphous and a porous surface of CCdBE. The obtained results were confirmed using X-ray diffraction analysis.

Figure 5. SEM of chitosan (a) and crosslinked chitosan (b).
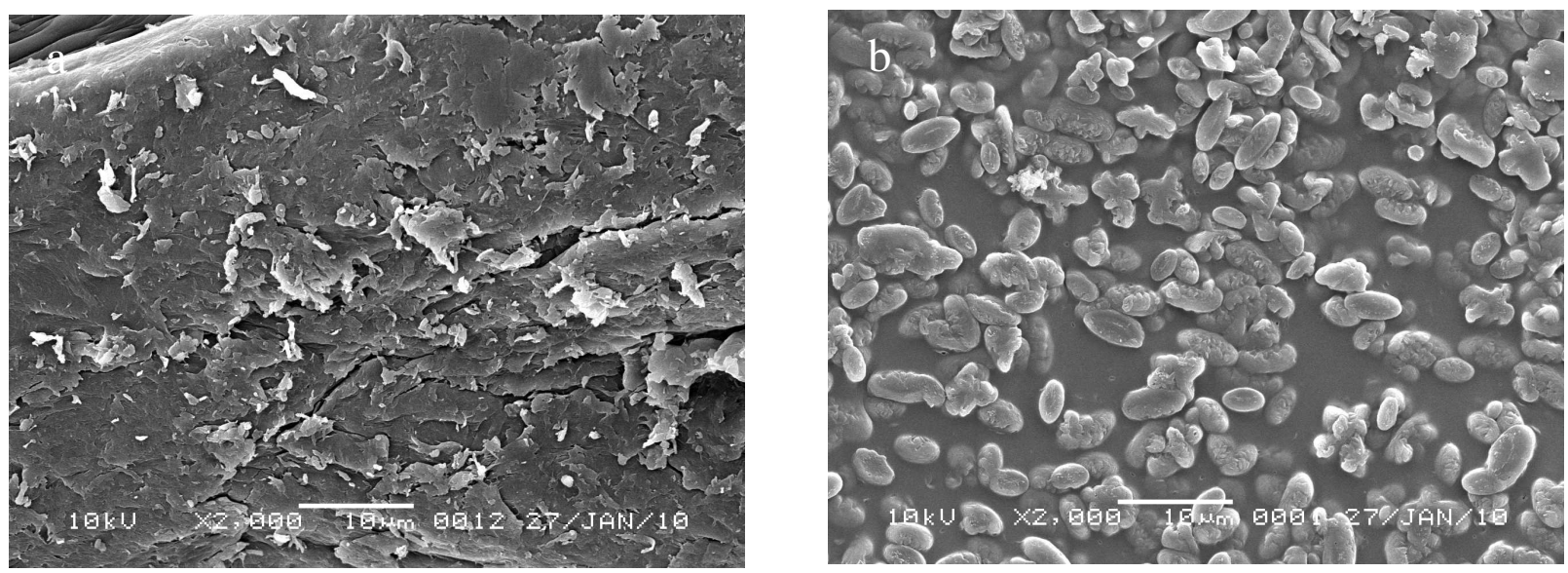

\subsection{Adsorption Behavior}

\subsubsection{Single Metal Ion Adsorption}

The adsorption capacities for metal ions onto CTS and CCdBE are presented in Table 2. It was observed that the adsorption capacities of $\mathrm{CCdBE}$ for $\mathrm{Pb}^{2+}$ and $\mathrm{Hg}^{2+}$ were higher than that of CTS. This could be attributed to the three-dimensional network of CCdBE that provided a cavity tailored to the volumetric space of $\mathrm{Pb}^{2+}$ and $\mathrm{Hg}^{2+}$ to adsorption. In addition, it can be seen that $\mathrm{CCdBE}$ has a better adsorption capacity for $\mathrm{Hg}^{2+}$ which further suggest that $\mathrm{CCdBE}$ could selectively adsorb $\mathrm{Hg}^{2+}$.

Table 2. Adsorption capacities of CTS and CCdBE for $\mathrm{Pb}^{2+}$ and $\mathrm{Hg}^{2+}$ at $\mathrm{pHs} 4$ and 6 .

\begin{tabular}{|c|c|c|c|c|}
\hline \multirow{3}{*}{ Adsorbent } & \multicolumn{4}{|c|}{ Adsorption capacities (mmol/g) } \\
\hline & \multicolumn{2}{|c|}{ pH 4} & \multicolumn{2}{|c|}{ pH 6} \\
\hline & $\mathbf{P b}^{2+}$ & $\mathrm{Hg}^{2+}$ & $\mathbf{P b}^{2+}$ & $\mathrm{Hg}^{2+}$ \\
\hline CTS & 0.82 & 0.33 & 0.94 & 1.48 \\
\hline $\mathrm{CCdBE}$ & 0.99 & 1.10 & 1.18 & 1.58 \\
\hline
\end{tabular}

\subsubsection{Two Metal Ion Co-Adsorption}

The selective adsorption of CTS and CCdBE for $\mathrm{Hg}^{2+}$ and $\mathrm{Pb}^{2+}$ from their solution is shown in Table 3. By comparing the selectivity of CCdBE for $\mathrm{Pb}^{2+}$ and $\mathrm{Hg}^{2+}$ with that of CTS, it can be found that the adsorption of $\mathrm{CCdBE}$ for $\mathrm{Hg}^{2+}$ is greater than that for $\mathrm{Pb}^{2+}$ at $\mathrm{pHs} 4$ and 6 , whereas the 
adsorption of $\mathrm{Hg}^{2+}$ by CTS was slightly higher than that of $\mathrm{Pb}^{2+}$ at $\mathrm{pH} 6$ while the opposite occurred at $\mathrm{pH} 4$.

From the selectivity coefficient $(\mathrm{k})$ results it can be observed that $\mathrm{K}_{\mathrm{Hg} / \mathrm{Pb}}$ has been improved 8 -fold at $\mathrm{pH} 4$ and 10.66-fold at $\mathrm{pH} 6$ by crosslinking of CTS into CCdBE. The results further suggest that $\mathrm{CCdBE}$ can selectively recognize $\mathrm{Hg}^{2+}$. Furthermore, it is concluded that a selective separation of $\mathrm{Pb}^{2+}$ and $\mathrm{Hg}^{2+}$ could be affected by using the CCdBE.

Table 3. Adsorption selectivity of CTS and $\mathrm{CCdBE}$ for $\mathrm{Pb}(\mathrm{II})$ and $\mathrm{Hg}(\mathrm{II})$ ions.

\begin{tabular}{|c|c|c|c|c|c|c|}
\hline \multirow{2}{*}{ Adsorbent } & \multicolumn{2}{|c|}{$\begin{array}{c}\text { Adsorption capacities } \\
(\mathrm{mmol} / \mathrm{g})\end{array}$} & \multirow{2}{*}{$\begin{array}{l}\text { Selectivity } \\
\text { coefficient } \\
\left(\mathrm{K}_{\mathrm{Hg}}{ }^{2+} / \mathrm{pb}^{2+}\right)\end{array}$} & \multicolumn{2}{|c|}{$\begin{array}{c}\text { Adsorption capacities } \\
(\mathrm{mmol} / \mathrm{g})\end{array}$} & \multirow{2}{*}{$\begin{array}{c}\text { Selectivity } \\
\text { coefficient } \\
\left(\mathrm{K}_{\mathrm{Hg}}{ }^{2+} / \mathbf{p b}^{2+}\right)\end{array}$} \\
\hline & $\begin{array}{l}\mathrm{pH} \mathrm{4} \\
\mathrm{Pb}^{2+}\end{array}$ & $\mathrm{Hg}^{2+}$ & & $\begin{array}{l}\mathrm{pH} 6 \\
\mathrm{~Pb}^{2+}\end{array}$ & $\mathbf{H g}^{2+}$ & \\
\hline CTS & 0.29 & 0.13 & 0.45 & 0.42 & 0.57 & 1.36 \\
\hline CCdBE & 0.12 & 0.96 & 8.00 & 0.13 & 1.38 & 10.62 \\
\hline
\end{tabular}

\subsubsection{Reusability}

It was observed that the adsorption capacities of $\mathrm{Pb}^{2+}$ decreased slightly from 1.2 to $1.08 \mathrm{mmol} / \mathrm{g}$ with increasing reuse cycles, and the adsorption capacity for $\mathrm{Pb}^{2+}$ is quite high even after reusing it 10 times, which indicates that the crosslinking in $\mathrm{CCdBE}$ results results in good reusability properties.

\section{Experimental Section}

\subsection{Materials}

Chitosan of medium molecular weight with $75-85 \%$ deacetylation, 3,4-dihydroxybenzaldehyde bis(2-chloroethyl)ether and zinc chloride were purchased from Sigma-Aldrich Company (St. Louis, MO, USA). All aqueous solutions were prepared with deionized water that had been passed through a Millipore Milli-Q Plus water purification system (Millipore, Bedford, MA, USA). The metal salts chosen for this study $\left(\left[\mathrm{PbCl}_{2}\right.\right.$ and $\left.\mathrm{Hg}\left(\mathrm{NO}_{3}\right) \cdot 0.5 \mathrm{H}_{2} \mathrm{O}\right]$ were reagent grade. The compound $2,3,11$, 12[4,4'-diformyl dibenzo]-1,4,7,10,13,16-hexaoxacyclooctadeca-2,11-diene (3) was synthesized using a previously reported procedure [20].

\subsection{Synthesis of Crosslinked Chitosan diBenzocrown Ether (CCdBE) (4)}

Powdered chitosan (1.13 g, 0.005 mol glucosamine residues) was dissolved in $20 \mathrm{~mL}$ of $10 \%$ (wt) acetic acid solution prepared in water to which ethanol $(20 \mathrm{~mL})$ was added and stirred using a magnetic stirrer for $30 \mathrm{~min}$ at $40^{\circ} \mathrm{C}$. Then, $4^{\prime}, 4^{\prime \prime}$-diformyldibenzo-18-c-6 crown ether (3), which was dissolved in chloroform-ethanol mixture $(1: 1,5 \mathrm{~mL})$ was slowly added dropwise into the above solution under nitrogen. The reaction mixture was irradiated in a microwave oven (Daewoo MW 800 $\mathrm{W}$ domestic type oven) at $10 \%$ intensity for $10 \mathrm{~min}$. The reaction mixture was cooled and neutralized with sodium carbonate solution. The liquid was decanted from the reaction mixture. The remaining residue was washed with distilled water, and subsequently the aqueous layer was decanted. Washing and decantation were repeated twice with water and ethyl alcohol. The residue was dried under a reduced pressure overnight giving a pale brown fibrous solid ( $85 \%$ yield). 


\subsection{Structural Characterization of Chitosan-Crown Ether}

\subsubsection{Elemental Analysis}

The elemental analysis was performed on a Perkin Elmer CHNSO analyzer, model no. 2400 (Perkin Elmer, Inc., Waltham, MA, USA).

\subsubsection{Infrared Spectra Analysis}

IR analysis (Perkin Elmer FT-IR, Waltham, MA,USA) was employed to confirm the changes in functional groups for natural (CTS) and crosslinked chitosan (CCdBE). Infrared spectra (400-4000 $\mathrm{cm}^{-1}$ ) were recorded using 100-mg $\mathrm{KBr}$ discs containing $2 \%$ of chitosan (CTS) or crosslinked chitosan (CCdBE).

\subsubsection{X-ray Diffraction Analysis}

The powder X-ray diffraction patterns of CTS and CCdBE were recorded with a Rigaku Ultima IV $\mathrm{X}$-ray diffractometer (Osaka, Japan) using X-ray tube $\mathrm{Cu}$ (1.540562). Samples were irradiated with monochromatized $\mathrm{Cu}-\mathrm{K} \alpha$ radiation and analyzed between $2 \theta$ angles of 5 and 40 . The voltage, the current, and the time per step were $40 \mathrm{mV}, 55 \mathrm{~mA}$ and $1 \mathrm{~s}$, respectively. Powder X-ray diffraction patterns were measured in order to evaluate the crystalline/amorphous character differences between CTS and CCdBE.

\subsubsection{Solid-state ${ }^{13} \mathrm{C}-\mathrm{NMR}$ Analysis}

Solid state ${ }^{13} \mathrm{C}$-NMR spectra were recorded at the Center for Pharmaceutical Biotechnology (University of Illinois at Chicago, IL, USA) on a Bruker Avance operating at $500 \mathrm{MHz}{ }^{1} \mathrm{H}$ frequency with a Bruker magic angle spinning probe with $4 \mathrm{~mm}$ diameter rotors. CPMAS spectra were collected at $9 \mathrm{kHz}$ spinning speed and $55 \mathrm{kHz}$ Two-Pulse Phase Modulation (TPPM) decoupling.

\subsubsection{Scanning Electron Microscopy (SEM) Studies}

The shape and surface characteristics of CTS and CCdBE were observed using a scanning electron microscope (SEM). Samples were mounted on an aluminum stub using a double-sided adhesive carbon tape and the flakes were then sputter-coated with gold palladium $(\mathrm{Au} / \mathrm{Pd})$ using a vacuum evaporator (Edwards). The coated samples were then scanned and photomicrographs were taken with a Jeol (Tokyo, Japan) JSM1-5510 SEM instrument.

\subsection{Adsorption Experiments}

\subsubsection{Single Metal Ion Adsorption Experiment}

A sample of CTS or CCdBE (25 mg) was added to a metal acetate solution $(100.0 \mathrm{~mL}$ of $10 \mathrm{ppm}$ initial $\mathrm{M}^{2+}$ concentration) with a given $\mathrm{pH}$ ( $\mathrm{pH} 4$ and 6) adjusted with $0.1 \mathrm{~m} / \mathrm{L}$ acetic acid. The solution 
was shaken for $24 \mathrm{~h}$ at $25^{\circ} \mathrm{C}$ and then filtered. The adsorption capacities of metal ions were obtained from initial and final concentrations of metal ions in the acetate solution as determined by a Shimadzu atomic adsorption spectrophotometer, model AA-460-13 (Shimadzu Corporation, Tokyo, Japan).

\subsubsection{Two Metal Ion Co-Adsorption Experiment}

A sample of CTS or CCdBE (25 mg) was added to acetate solution containing $\mathrm{Pb}^{2+}$ and $\mathrm{Mg}^{2+}$ ions (100.0 mL, initial concentration of single species $5 \mathrm{ppm}$ ) at $\mathrm{pH}$ values of 4 and 6 . The solution was shaken for $24 \mathrm{~h}$ at $25^{\circ} \mathrm{C}$ and then filtered. The contents of $\mathrm{M}^{2+}$ were determined from initial and final concentrations of metal ions in the acetate solution as determined by atomic adsorption spectrophotometry.

\subsubsection{Reusability Experiment}

The crosslinked chitosan $(\mathrm{CCdBE})$ adsorbed $\mathrm{Pb}^{2+}$ was dipped into stirring $0.1 \mathrm{~mol} / \mathrm{L} \mathrm{HCl}$ for $1 \mathrm{~h}$ at $25{ }^{\circ} \mathrm{C}$ to remove $\mathrm{Pb}^{2+}$, and then treated with $0.1 \mathrm{~mol} / \mathrm{L} \mathrm{NaOH}$ for $5-8 \mathrm{~h}$. Finally it was filtered and washed in turn with water, ethanol and ether. The CCdBE obtained was used in adsorption experiment and the process was repeated 10 times.

\section{Conclusions}

Microwave irradiation was utilized in the synthesis of a $\mathrm{N}$-Schiff base-type crosslinked chitosan crown ether $(\mathrm{CCdBE})$ by the reaction of $4^{\prime}, 4^{\prime \prime}$-diformyldibenzo-18-crown-6 with chitosan. Its adsorption selectivity and reusability was determined. The adsorption capacity of the obtained CCdBE was much higher for $\mathrm{Hg}^{2+}$ than that for $\mathrm{Pb}^{2+}$. The reported crosslinking method could retain higher adsorption capacity of CTS and, at the same time, improve the acidic resistance of CTS with a desirable selectivity towards mercury ions over lead ions.

\section{Acknowledgements}

The authors acknowledge the generous financial support from the Center of Excellence for Research in Engineering Materials (grant \# 430-CEREM-03), King Saud University and Ministry of Higher Education, Saudi Arabia.

\section{References and Notes}

1. Gotoh, T.; Matsushima, K.; Kikuchi, K.I. Adsorption of $\mathrm{Cu}$ and $\mathrm{Mn}$ on covalently crosslinked alginate gel beads. Chemosphere 2004, 55, 57-64.

2. Gotoh, T.; Matsushima, K.; Kikuchi, K.I. Preparation of alginate-chitosan hybrid gel beads and adsorption of divalent metal ions. Chemosphere 2004, 55, 135-140.

3. Cao, J.; Tan, Y.; Che, Y.; Xin, H. Novel complex gel beads composed of hydrolyzed polyacrylamide and chitosan: An effective adsorbent for the removal of heavy metal from aqueous solution. Bioresource Technol. 2010, 101, 2558-2561. 
4. Monier, M.; Ayad, D.M.; Sarhan, A.A. Adsorption of $\mathrm{Cu}(\mathrm{II}), \mathrm{Hg}(\mathrm{II})$, and $\mathrm{Ni}(\mathrm{II})$ ions by modified natural wool chelating fibers. J. Hazard. Mater. 2010, 176, 348-355.

5. Wu, F.C.; Tseng, R.L.; Juang, R.S. Kinetic modeling of liquid-phase adsorption of reactive dyes and metal ions on chitosan. Water Res. 2001, 35, 613-618.

6. Zhoua, L.; Wang, Y.; Liu, Z.; Huang, Q. Characteristics of equilibrium, kinetics studies for adsorption of $\mathrm{Hg}(\mathrm{II}), \mathrm{Cu}(\mathrm{II})$, and $\mathrm{Ni}$ (II) ions by thiourea-modified magnetic chitosan microspheres. J. Hazard. Mater. 2009, 161, 995-1002.

7. Evans, J.R.; Davids, W.G.; MacRae, J.D.; Amirbahman, A. Kinetics of cadmium uptake by chitosan-based crab shells. Water Res. 2002, 36, 3219-3226.

8. Rangel-Mendez, J.R.; Monroy-Zepeda, R.; Leyva-Ramos, E.; Diaz-Flores, P.E.; Shirai, K. Chitosan selectivity for removing cadmium (II), copper (II), and lead (II) from aqueous phase: $\mathrm{pH}$ and organic matter effect. J. Hazard. Mater. 2009, 162, 503-511.

9. Deans, R.J.; Dixon, B.G. Uptake of $\mathrm{Pb}^{2+}$ and $\mathrm{Cu}^{2+}$ by novel biopolymers. Water Res. 1992, 26, 469-472.

10. Kurita, K.; Sannan, T.; Iwakura, Y. Studies on Chitin. VI. Binding of Metal Cations. J. Appl. Polym. Sci. 1979, 23, 511-515.

11. Loretz, B.; Bernkop-Schnurch, A. In vitro evaluation of chitosan-EDTA conjugate polyplexes as a nanoparticulate gene delivery system. AAPS J. 2006, 8, E756-E764.

12. Masri, M.S.; Randall, V.G.; Pittman, A.G. Removal of metallic ions by partially polyamine polymers. Polym. Preprints-Am. 1978, 19, 483-488.

13. Jin, L.; Bai, R. Mechanisms of lead adsorption of chitosan/PVA hydrogel beads. Langmuir 2002, 18, 9765-9770.

14. Schmuhl, R.; Krieg, H.M.; Keizer, K. Adsorption of $\mathrm{Cu}(\mathrm{II})$ and $\mathrm{Cr}(\mathrm{VI})$ ions by chitosan: kinetics and equilibrium studies. Water SA 2001, 27, 1-8.

15. Guibal, E.; Jansson-Charrier, M.; Saucedo, I.; Le Cloirec, P. Enhancement of metal ion sorption performances of chitosan: effect of the structure on the diffusion properties. Langmuir 1995, 11, 591-598.

16. No, H.K.; Meyers, S.P.J. Crawfish chitosan as a coagulant in recovery of organic compounds from seafood processing streams. J. Agric. Food Chem. 1989, 37, 580-583.

17. Yi, Y.; Wang, Y.; Liu, H. Preparation of new crosslinked chitosan with crown ether and their adsorption for silver ion for antibacterial activities. Carbohydr. Polym. 2003, 53, 425-430.

18. Xing, R.G.; Liu, S.; Yu, H.H.; Guo, Z.Y.; Wang, P.B.; Li, C.P.; Li, Z.; Li, P.C. Salt-assisted acid hydrolysis of chitosan to oligomers under microwave irradiation. Carbohydr. Res. 2005, 340, 2150-2153.

19. Sha, Y.W.; Wang, Y.; Ge, J.; Wang, X. Application of microwave irradiation in the synthesis of heterocyclic compounds. Chin. J. Org. Chem. 2001, 21, 102-115.

20. Wada, F.; Hirayama, H.; Namiki, H.; Kikukawa, K.; Matsuda, T. New applications of crown ethers. II. Synthesis of 4'-Formylbenzocrown Ethers. Bull. Chem. Soc. Jpn. 1980, 53, 1473-1474.

21. Samuels, R.J. Solid-state characterization of the structure of chitosan films. J. Polym. Sci. Part B: Polym. Phys. 1981, 19, 1081-1105.

22. Yen, M.-T.; Yang, J.-H.; Mau, J.-L. Physicochemical characterization of chitin and chitosan from crab shells. Carbohydr. Polym. 2009, 75, 15-21. 
23. Tang, X.-H.; Tan, S.-Y.; Wang, Y.-T. Study of the synthesis of chitosan derivatives containing benzo-21-crown-7 and their adsorption properties for metal ions. J. Appl. Polym. Sci. 2001, 83, 1886-1891.

Sample Availability: Samples of compounds $\mathbf{3}$ and $\mathbf{4}$ are available from the authors.

(C) 2010 by the authors; licensee MDPI, Basel, Switzerland. This article is an open access article distributed under the terms and conditions of the Creative Commons Attribution license (http://creativecommons.org/licenses/by/3.0/). 